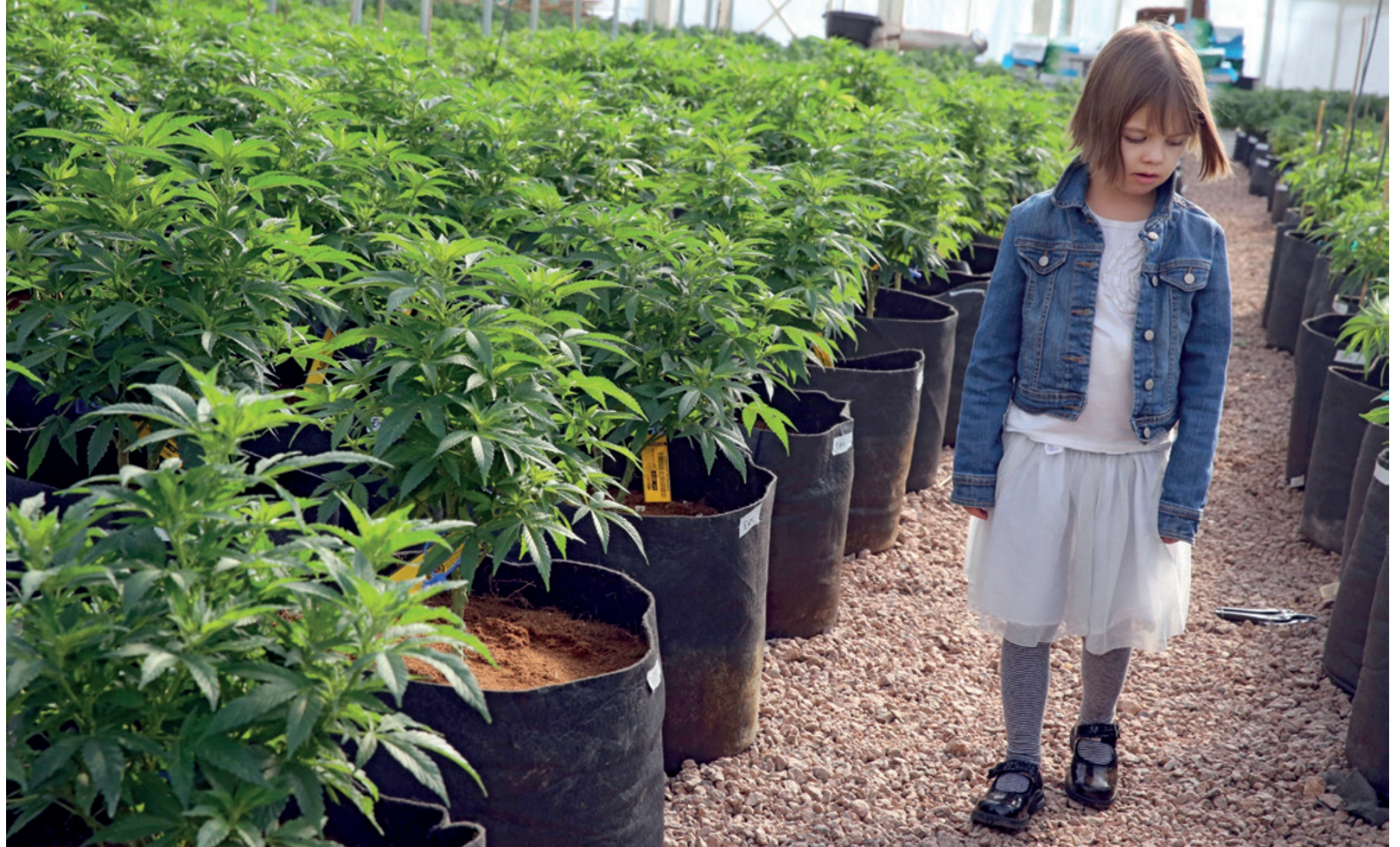

Cannabis plants grown in Colorado were used to treat Charlotte's epilepsy, but researchers are heading to Israel to study the drug.

\title{
Research without prejudice
}

\section{How one Mediterranean country is pushing the frontiers of medical cannabis knowledge.}

\section{BY EMILY SOHN}

A lan Shackelford is intent on finding out why some of his patients respond so well to cannabis. But despite living in Colorado, the US state with some of the most liberal medical marijuana laws, he has had to travel to Israel to continue his research.

Shackelford's road to the Mediterranean nation started in 2012. While working in occupational medicine and injury rehabilitation private practice, he got a call from a mother whose 5-year-old daughter Charlotte was having 300 seizures a week and not responding to treatment. The family were desperate for help. They had heard that medical marijuana was being used to treat epilepsy, but had been turned away by doctors when they asked for the treatment for Charlotte. Although Shackelford had finally agreed to treat his older patients with cannabis a few years earlier, he was particularly reluctant to give the herb to such a young child. But, after digging into the literature, Shackelford agreed to treat Charlotte with a specific strain high in cannabidiol (CBD), which a friend of the family converted into an oil extract.

Now 8, Charlotte is thriving. She takes the oil every day and has just one seizure every month or so, Shackelford reports. He has seen other, similar stories, but such case reports and testimonials do not constitute peer-reviewed evidence. However, when he looked into getting permission for a trial, he was overwhelmed by the bureaucracy involved. At a federal level, cannabis is classified as a schedule 1 drug, meaning that it has no known medical value. Unless the study looks at the harm the drug might cause, permission for cannabis research can be harder to obtain than that for heroin or cocaine, says Shackelford. "There is a bias against doing trials here that might show a benefit."

Frustrated, he went to Israel - one of only a few countries with a national medical cannabis research programme. Shackelford was attracted by the country's 50 -year history of study into potential uses for the drug, as well as a supportive regulatory atmosphere that is not found anywhere else. "The attitude towards research in Israel has always been different and not coloured by prejudice or propaganda," Shackelford says. Reputable researchers who want to study cannabis are not simply dismissed, he says, "which is often the case in other countries, including, notoriously, the US".

\section{Other researchers $\rightarrow$ NATURE.COM}

and entrepreneurs Read more about the are, like Shackelford, research challenges at: turning to Israel to go.nature.com/tg $6 \mathrm{~d} 9 \mathrm{v}$ further research into cannabis. "It's a topic in which, maybe surprisingly, Israel is pushing ahead," says Raphael Mechoulam, a chemist at The Hebrew University of Jerusalem.

\section{GOOD PARENTING}

The modern era of cannabis research started in Israel, spearheaded by Mechoulam (see page S10) - often called the father of medical cannabis. In fact, Shackelford's decision to treat Charlotte was influenced by Mechoulam's research into CBD (J. M. Cunha et al. Pharmacology 21, 175-185; 1980).

Today, Israel is one of many places that boasts a broad supportive atmosphere for cannabis: some $75 \%$ of the population back its medicinal use, and in 2013 the Orthodox rabbi Efraim Zalmanovich ruled that medical cannabis was kosher.

Israel also seems to nurture an entrepreneurial spirit, which is apparent in Mechoulam's story. Originally from Bulgaria, Mechoulam began investigating cannabis in the 1960s while working at the Weizmann Institute of Science in Rehovot. He was attracted by the mystery: although the active constituents of coca leaves and opium were known, cannabis was still largely unstudied.

Before he could start his research, Mechoulam needed to procure some cannabis. 
Unsure how to get it, he asked his superior if he knew anyone in the police department who could give him some of their confiscated supplies. The administrator called the police, and Mechoulam recalls hearing someone on the other end of the line ask, "Is he reliable?" Once assured, the police invited him to come by. "I went there and picked up five kilos of hashish," Mechoulam says. However, he soon found out that this was not the correct procedure. "It turned out we had broken the law, and the police had broken the law. We should have gotten all kinds of permits." But he was not punished. "I went and apologized," Mechoulam says. He filled in the proper paperwork: "And for years, I continued to get legal cannabis from the police."

With a reliable supply of cannabis, Mechoulam and his team made rapid progress. In 1963, they determined the structure of CBD. The following year, they isolated tetrahydrocannabinol (THC), the main psychoactive substance in cannabis. Mechoulam also helped to discover anandamide, a naturally occurring chemical in the brain that binds to the same receptor as THC, sparking interest in the 'endocannabinoid' system (see page S6).

Currently, says Mechoulam, there are about ten research groups in the field in Israel, working on cannabis as a treatment for conditions such as post-traumatic stress disorder (PTSD), epilepsy, chronic pain, rheumatoid arthritis, fibromyalgia and Crohn's disease (see page S15). At 84 years old, Mechoulam is still an active researcher and is currently planning a trial of cannabis in people with brain cancer. His adopted coun-

try has long celebrated him, and he is free of the reputation-threatening stigma that is often attached to cannabis researchers elsewhere.

This is in contrast to the saga of US psy-

\section{"They were} actually there to very sincerely look into the matter of when drugs are useful." the institution maintains that its decision not to renew her contract was unrelated to the politics of medical marijuana research.

Sisley flew to Israel earlier this year to investigate the potential of moving the research there, and describes the experience as eye opening. "It was a joy to be there," she says. "None of the researchers perceived marijuana as an impediment to science. They just viewed it as another study drug." For the time being, Sisley has decided to remain in the United States as an independent researcher. Her study has received approval from an independent institutional review board and, with her team, she has secured funding and found space in which to conduct the study. The National Institute on Drug Abuse will supply 4 strains when the approval process is complete.

\section{SMALL IS BEAUTIFUL}

Working in a relatively small country with a limited number of research facilities increases the chance that scientists will talk across disciplines, particularly for researchers in a niche field such as cannabis. Immunologist Ruth Gallily recalls how her interest in the drug began after a chance encounter with pharmacologist Esther Shohami some 15 years ago while they were both working at The Hebrew University of Jerusalem. Shohami described her experiments in which mice with head trauma showed great improvement when treated with a CBD-derivative (D. Panikashvili et al. Nature 413, 527-531;2001). Gallily asked to see the animals' brains and was surprised to see that those treated with the derivative showed suppression of a key inflammatory protein. This led her to study the anti-inflammatory effects of CBD and its potential to treat conditions such as diabetes, heart disease and multiple sclerosis. "In a small place, you meet people again and again," Gallily says. "You begin to get ideas from others."

Timna Naftali, a gastroenterologist at Meir Hospital in Kfar Saba, says that her experience of seeking approval for two trials of medical marijuana as a treatment for Crohn's disease was smooth - a process that could have been much more difficult had she been working in the United States or even Canada. "I was expecting an approach like that of a drug authority that would say, 'no' to everything because they are there to stop people from using drugs," says Naftali. "But they were actually there to very sincerely try and look into the matter of when drugs are useful and when they are not."

Israeli technology companies are also involved in medical cannabis, developing delivery systems such as sustained-release pills and vaporizers. The country is even attracting foreign companies, who want to base their research and development (R\&D) centres in Israel. Eyal Ballan is co-founder and chief scientist at drug-development company Cannabics Pharmaceuticals, based in Bethesda, Maryland, the R\&D arm of which is in Israel.

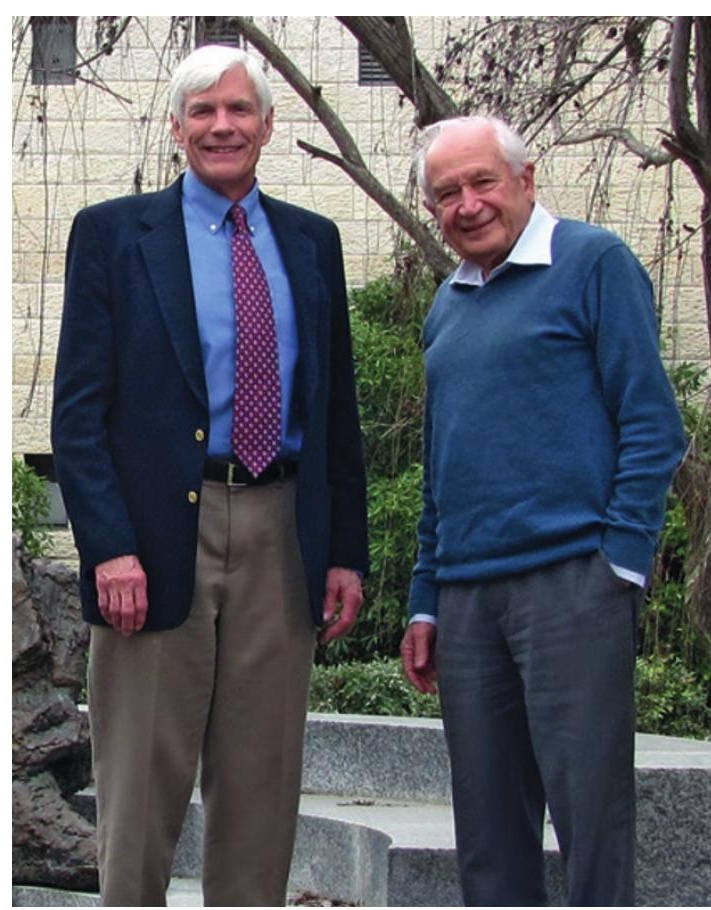

Alan Shackelford (left) and Raphael Mechoulam.

Ballan says that he has received calls from researchers in places such as Brazil, Germany and the United States. "Sometimes they want the product itself," he says. "Sometimes they need help with regulations to promote medical cannabis in their states. Sometimes they wish to test their own products in Israel." This experience is echoed by Boaz Wachtel, cofounder of Phytotech Medical — an Australian cannabis research company that also bases its R\&D in Israel. Once every couple of weeks, he says, he hears from researchers and executives looking for advice or seeking research collaborators.

Israel's approach to cannabis is more liberal than those of most countries, but it is far from a free-for-all. The drug remains illegal for recreational use (although there are signs that this may be changing). Israel also refuses to export cannabis to other countries, despite plenty of interest. Many researchers consider that this kind of balanced approach may be an important factor in why cannabis research in Israel is taken seriously; the herb is treated as a drug that needs to be studied in order to be safely used, just like any other. "We have to know exactly what amounts of CBD and THC people are getting," says Mechoulam. "These things have to be well-regulated."

These policies have served the country well. "The Israeli national medical cannabis programme is considered a success," says Wachtel. "I see a great movement, from the United States, from Canada, from many other countries, of people who want to get into this field. We are awash with newcomers."

Emily Sohn is a freelance journalist based in Minneapolis. 